\title{
Production of Coir-Jute Blended Yarn: A Comparative Study on the Performance of Jute and Coir-Jute Blended Yarn
}

\author{
Md.Rezaul Karim ${ }^{1}$, Rabaca Sultana ${ }^{1 *}$, Pallab Barua ${ }^{1}$, Sadia Mehrin², Akhil Indu Dhali ${ }^{3}$ and Tarikul Islam ${ }^{4}$ \\ ${ }^{1}$ Department of Textile Engineering, Port City International University, Chittagong, Bangladesh
}

${ }^{2}$ Department of Textile Engineering, Bangladesh University of Business and Technology, Dhaka-1216, Bangladesh

${ }^{3}$ Department of Textile Engineering, Mawlana Bhashani Science and Technology University, Tangail-1902, Bangladesh

${ }^{4}$ Department of Textile Engineering, Jashore University of Science and Technology, Jashore-7408, Bangladesh

*Corresponding author: Rabaca Sultana, Department of Textile Engineering, Port City International University, Chittagong, Bangladesh.
Received Date: June 14, 2019

Published Date: June 21, 2019

\begin{abstract}
The demand for environmentally friendly fiber is increasing day by day. Jute is a source of eco- friendly fiber, but years to come, it will be more expensive as the production of jute is decreasing because of the availability of synthetic fiber at low cost. Coir fibers obtained from the husk of the coconut are highly available in the coastal area of Bangladesh, which is a good source of environmental friendly fiber. There is a large demand of jute products all over the world. If we utilize the coir fiber by blending it with jute, it can be a good solution to meet the demand. A method has been developed to produce coir-jute blended yarn and compare the property of blended yarn with $100 \%$ jute yarn. Coir fiber was treated with $\mathrm{NaOH}$ to achieve softer coir fiber. Coir fiber was blended with jute fiber at the proportion of 50:50 to produce yarn of 16lbs having quality ratio more than $121 \%$ and an acceptable range of co-efficient of variation of strength.
\end{abstract}

Keywords: Blended yarn; Coir fiber; Eco-friendly; Jute fiber

\section{Introduction}

Blended fiber means unique fiber with unique characteristics. When two or more fibers mixed, a new fiber found with a new signature, which is called blended fiber. Generally, fiber is blended to gain a specific nature of a required product. That is why Coir and Jute fiber blended in this research. Coir fiber obtained from the husk of the Coconut [1]. Here, Husk means the outer shell of coconut [2]. Coconut is a palm plant and it is found in the humid tropical region as like Coastal areas [3]. Asia and East Africa are mainly farming the Coconut plant extensively [4]. Coir fiber has some physical properties such as it is 6-8 inches in length, the diameter is 0.1 $1.5 \mathrm{~mm}$, density is 1.40 , tenacity is 10.0 , breaking elongation is $30 \%$, and moisture at $65 \% \mathrm{RH}$ is $10.50 \%$ [5]. Coir fiber has a wide range of applications. For instance, motorcycle helmet, cement, plaster, house construction, slope stabilization, wall paneling system, slabs, concrete [6]. Moreover, it has some general uses i.e. ropes, mattresses, floor mats, vehicle seats, brushes, brooms, furniture, etc. $[6,7]$.
On the other hand, Jute is a lengthy vegetable fiber which is very mild [8]. Jute fiber can be spun into coarse and farm threads [8]. It is one of the cheapest natural bast fiber, and its source of origin is Corchorus plants and that is why its scientific name is Corchorus Capsularis [9]. It is available in Asian region but nowadays, some other regions are also cultivating Jute. Few countries are farming jute enormously \& they are Bangladesh, India, China, Thailand, Nepal, Indonesia, Brazil $[10,11]$. Cultivation of Jute depends on some climatic factors such as temperature, humidity, rainfall etc. and Jute has a contribution to the national economy in some country [12]. Jute fiber also has some physical properties such as its length is $1.5-4 \mathrm{~mm}$, the diameter is $0.015-0.020 \mathrm{~mm}$, Strength is $3-4 \mathrm{gm} / \mathrm{den}$, elongation is $1.7 \%$ at the break, Moisture regain is $13.75 \%$ [13]. Jute product is important both for human being and environment as it is biodegradable, eco-friendly and non-toxic [14]. Jute is a versatile fiber, and there is a plethora of applications of jute fiber such as sacking, foot wears, bags and soft luggage, tablecloth, 
bed cover, cushion cover, napkins, sofa cover, blankets, floor cover, ornaments, etc. [15].

Here, this research mainly shows the performance of Jute and a comparative study on the performance of coir-jute blended yarn.

\section{Materials and Methods}

\section{Materials}

- Raw coconut fiber

- Jute fiber procured from KFD jute mill.

- $\quad$ Sodium Hydroxide

- $\quad$ Acetic acid

\section{Methods}

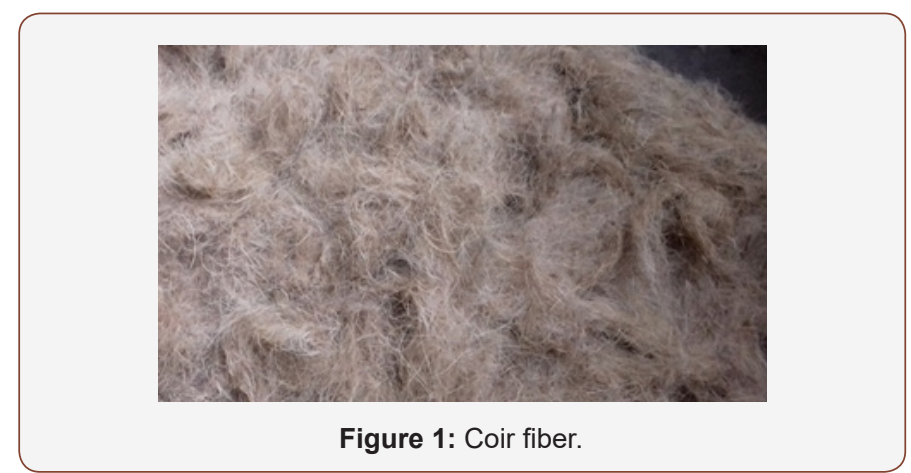

Softening of coir fiber: Raw coir fiber was immersed in a solution of $\mathrm{NaOH}$ and wetting agent in KFD jute mill in 1:25material to liquor ratio and heated for 1 hour at $100^{\circ} \mathrm{C}$.After softening the coir fiber washed with warm water and neutralized with $5 \%(\mathrm{w} / \mathrm{w})$ acetic acid solution. After neutralization, the coir fiber was washed with normal water and dried in air (Figures 1\&2).

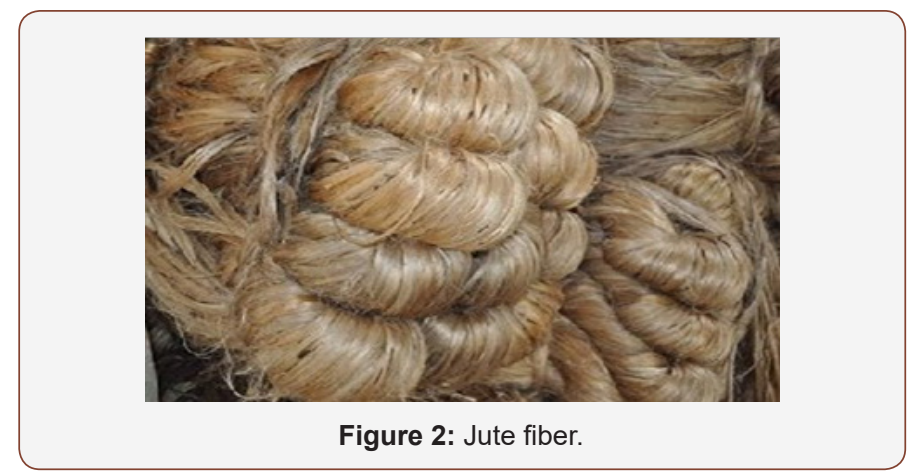

Batching of jute: Jute fiber was batched with $24 \%$ emulsion used in jute processing and kept in a pile for $72 \mathrm{hrs}$ (Figures $3 \& 4$ ).

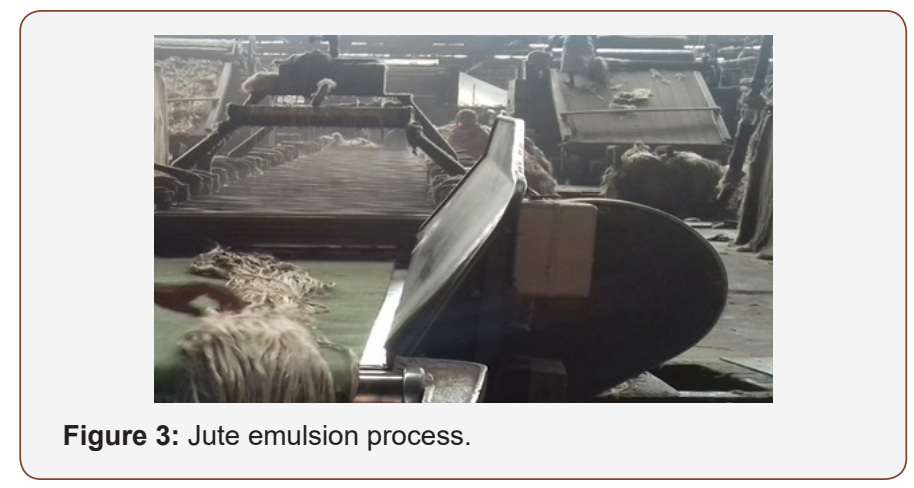

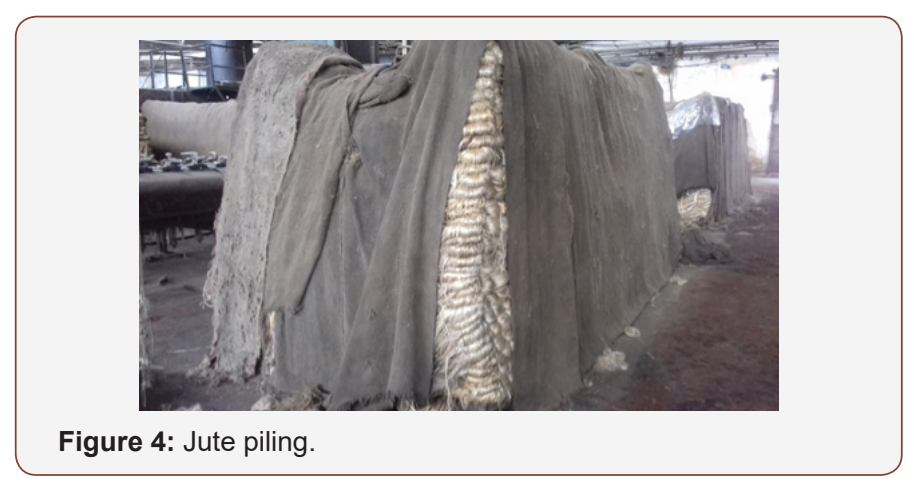

Preparation of blended yarn: The soften coir fiber and jute fibers blended in the following sequence:

- $\quad$ Soften coir fiber and jute fiber mixed by hand in 50:50 and then passed through breaker card to remove dust and other impurities and to form sliver rolls.

- The sliver rolls then fed to finisher card which make the sliver more uniform, parallel and regular in length and weight.

- The sliver rolls then passed through the first, second\& third drawing frame to reduce the sliver width and thickness.

- The sliver rolls then carried out in the spinning frame to produce the blended yarn of $16 \mathrm{lbs} / \mathrm{spy}$.

Preparation of jute yarn: The jute yarn made by the following sequence:

- $\quad$ The batched jute fiber passed through breaker card to remove dust and other impurities and to form sliver rolls.

- The sliver rolls then fed to finisher card which make the sliver more uniform, parallel and regular in length and weight.

- $\quad$ The sliver rolls then passed through the first, second \& third drawing frame to reduce the sliver width and thickness.

- The sliver rolls then carried out in the spinning frame to produce the jute yarn of 16lbs/spy (Figure 5).

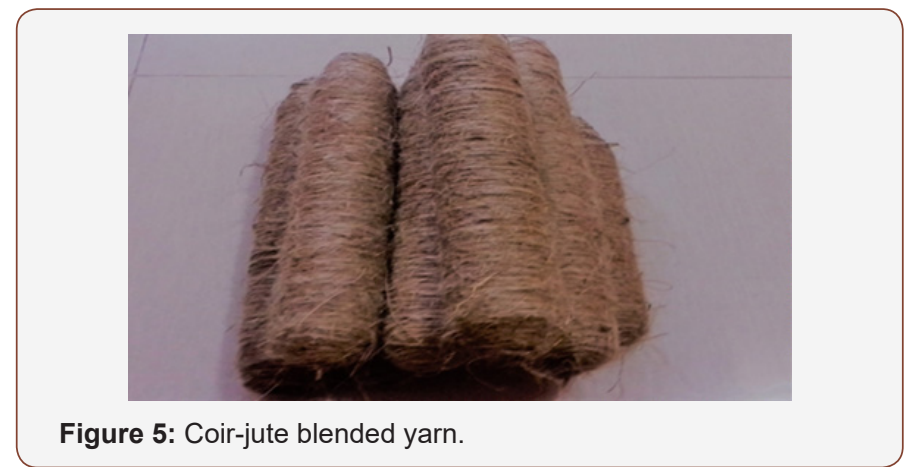

\section{Results and Discussion}

Table 1: Properties of coir-jute blended yarn.

\begin{tabular}{|c|c|}
\hline Properties of the Yarn & Value \\
\hline Count of the yarn & $16 \mathrm{lbs} / \mathrm{spy}$ \\
\hline Tensile strength & $19.45 \mathrm{lbs}$ \\
\hline Quality ratio & $121.56 \%$ \\
\hline Coefficient of variation of strength & $12.13 \%$ \\
\hline Twist per inch & 3.2 \\
\hline
\end{tabular}


Properties of the blended yarn determined by standard testing methods. The results discussed below (Tables 1\&2):

Table 2: Properties of jute yarn.

\begin{tabular}{|c|c|}
\hline Properties of the Yarn & Value \\
\hline Count of the yarn & $16 \mathrm{lbs} / \mathrm{spy}$ \\
\hline Tensile strength & $15.19 \mathrm{lbs}$ \\
\hline Quality ratio & $107.27 \%$ \\
\hline Coefficient of variation of strength & 14.18 \\
\hline Twist per inch & 3.2 \\
\hline
\end{tabular}



From the figure 6, it is seen that the property of coir-jute blended yarn is better than $100 \%$ jute yarn. The Quality ratio, Tensile strength, CV\% of the strength of the coir-jute blended yarn is better than $100 \%$ jute yarn.

\section{Conclusion}

The properties of blended yarn of coir fiber and jute fiber in the ratio of 50:50 show that it is possible to produce $16 \mathrm{lbs} / \mathrm{spy}$ in 50:50 proportions by jute spinning system. Tensile strength of the yarn was $19.75 \mathrm{lbs}$, coefficient of variation of the strength was $12.13 \%$ and the quality ratio was $121.56 \%$, which are within an acceptable range. The coefficient of variation of the strength $12.13 \%$ indicates uniformity of the blended yarn. From the above discussion, the method of developing blended yarn seems to be effective.

\section{Author Contributions}

This project work has been done under the supervision of M.R.K. with the help of T.I. Moreover, R.S. and P.B. have done the specimen fabrication, characterization, testing, data analysis, and presentation part with the help of A.I.D. and S.M. All authors read and finally approved the manuscript.

\section{Conflicts of interest}

The authors declare that they have no competing interests.

\section{References}

1. Wikipedia, the free Encyclopedia, Coir.

2. Ede AN, Agbede JO (2015) Use of coconut husk fiber for improved compressive and flexural strength of concrete. International Journal of Scientific \& Engineering Research 6(2): 968-974.

3. Cirad (Agricultural research for development).

4. Aziz MA, Paramasivam MA, Lee SL (1984) Concrete reinforced with natural fibres, new reinforced concrete. 106-140.

5. Alam MF. An overview of Coconut or Coir Fiber, Textile Learner (One stop solution for Textiles).

6. Zachar J, Claisse P, Naik T, Ganjian E (2010) Coconut fiber-a versatile material and its application in engineering. International Conference on Sustainable Construction Materials and Technologies.

7. Uses of Coconut.

8. Wikipedia, The free Encyclopedia, Jute.

9. Singh H, Preet Singh JI, Sinngh S, Dhawan V, Tiwari SK (2018) A brief review of jute fiber and its composites. Materials Today Proceedings 5(14): 28427-28437.

10. Thiruchitrambalam M, Athijayamani A, Sathiyamurth S, Abu Thaheer AS (2010) A review on the natural fiber-reinforced polymer composites for the development roselle fiber-reinforced composite. Journal of Natural Fiber 7(4): 307-323.

11. Faruk O, Bledzki AK, Fink HP, Sain M (2012) Bio composites reinforced with natural fibers: 2000-2010. Progress in Polymer Science 37(11): 1552-1596.

12. Islam MM, Begum S, Maqsudul Alam AK, Ahmed I, Alamgir A (2009) Study the Impact of Climatic changes on Jute Production in Bangladesh, International Conference on Global Climate Change and its effects on Food security and South East Asia.

13. Textile fashion study, Physical \& chemical properties of jute. Identity of jute fiber. Textile Engineering and Fashion Design Blog.

14. Shahinur S, Hasan M, Ahsan Q, Saha DK, Islam MS (2015) Characterization on the Properties of the Jute Fiber at different portions. International Journal of Public Science, Volume 2015: 6.

15. Roy S (2010) Applications on natural fiber (jute) Products. International Symposium on Renewal Feedstock for Biofuel and Bio-based Products, Austin, USA. 